\title{
Haladaptatus litoreus sp. nov., an extremely halophilic archaeon from a marine solar saltern, and emended description of the genus Haladaptatus
}

Correspondence
Heng-Lin Cui
cuihenglin@ujs.edu.cn
Heng-Lin Cui, ${ }^{1}$ Fang-Fang Sun, ${ }^{1}$ Xia Gao, ${ }^{1}$ Ying Dong, ${ }^{1}$ Xue-Wei Xu, ${ }^{2}$
Yu-Guang Zhou, ${ }^{3}$ Hong-Can Liu, ${ }^{3}$ Aharon Oren ${ }^{4}$ and Pei-Jin Zhou ${ }^{3}$

\author{
${ }^{1}$ School of Food and Biological Engineering, Jiangsu University, Zhenjiang 212013, PR China \\ ${ }^{2}$ Second Institute of Oceanography, State Oceanic Administration, Hangzhou 310012, PR China \\ ${ }^{3}$ State Key Laboratory of Microbial Resources, Institute of Microbiology, Chinese Academy of \\ Sciences, Beijing 100101, PR China \\ ${ }^{4}$ Department of Plant and Environmental Sciences, The Institute of Life Sciences, and The Moshe \\ Shilo Minerva Center for Marine Biogeochemistry, The Hebrew University of Jerusalem, 91904 \\ Jerusalem, Israel
}

Two extremely halophilic archaea, strains $\mathrm{RO} 1-28^{\top}$ and $\mathrm{RO} 1-22$, were isolated from a marine solar saltern in Jiangsu, China. Both strains required at least $0.05 \mathrm{M} \mathrm{Mg}^{2+}$ and $1.7 \mathrm{M} \mathrm{NaCl}$ for growth. They were able to grow over a $\mathrm{pH}$ range of 6.0-8.5 and a temperature range of 25$55^{\circ} \mathrm{C}$, with optimal $\mathrm{pH}$ of 7.0 and optimal temperature of $37-40{ }^{\circ} \mathrm{C}$. Based on $16 \mathrm{~S}$ rRNA gene sequence analysis, strains $\mathrm{RO} 1-28^{\mathrm{T}}$ and $\mathrm{RO} 1-22$ were closely related to Haladaptatus paucihalophilus, the single species of the genus Haladaptatus, with similarities of 94.0-95.2\%. The major polar lipids of the two strains were phosphatidylglycerol, phosphatidylglycerol phosphate methyl ester, phosphatidylglycerol sulfate and three glycolipids chromatographically identical to the glycolipids of Haladaptatus paucihalophilus JCM $13897^{\top}$. Both strains RO1-28 and RO1-22 had a DNA G +C content of 54.0 mol\% (HPLC). The DNA-DNA hybridization value between the two strains was more than $70 \%$ (92\%) and both strains showed low levels of DNADNA relatedness (32\% and $33 \%$ ) with Haladaptatus paucihalophilus JCM $13897^{\top}$. It was concluded that strains RO1-28 ${ }^{\top}$ and RO1-22 represent a novel species of the genus Haladaptatus, for which the name Haladaptatus litoreus sp. nov. is proposed. The type strain is RO1-28 ${ }^{\top}$ (=CGMCC $1.7737^{\top}=$ JCM $\left.15771^{\top}\right)$.
Extremely halophilic aerobic archaea, members of the order Halobacteriales, have been mainly isolated from diverse hypersaline environments such as salt lakes, artificial crystallizer ponds of marine solar salterns, salty fermented food and salted hides (Oren, 2006). A few of them can also be found in low-salt habitats such as lowsalt, sulfide-rich springs and seashore marshes (Purdy et al., 2004; Savage et al., 2007, 2008). The genus Haladaptatus was first proposed by Savage et al. to accommodate the species Haladaptatus paucihalophilus, which is coccus- or coccobacillus-shaped and was isolated from Zodletone

Abbreviations: PG, phosphatidylglycerol; PGP-Me, phosphatidylglycerol phosphate methyl ester; PGS, phosphatidylglycerol sulfate.

The GenBank/EMBL/DDBJ accession numbers for the 16S rRNA gene sequences of strains RO1-28 ${ }^{\top}$ and RO1-22 are EU887285 and FJ773394, respectively.

Scanning electron micrographs and thin-layer chromatograms are available with the online version of this paper.
Spring, a sulfide- and sulfur-rich but low $\mathrm{NaCl}$ concentration spring in south-western Oklahoma, USA (Savage et al., 2007). Strains of Haladaptatus paucihalophilus can grow in a wide range of salt concentrations $(0.8-5.1 \mathrm{M})$ and their cells remain viable in distilled water after prolonged incubation, providing evidence that they are adapted to relatively low-salt systems or fluctuating salt concentrations. Each strain of Haladaptatus paucihalophilus possesses at least two heterogeneous 16S rRNA gene sequences with 2.7-4.1\% divergence. During our surveys on halophilic archaeal diversity of marine solar salterns of Eastern China, two halophilic archaeal isolates related to Haladaptatus paucihalophilus were obtained. In this study, we characterize the two strains, RO1-28 ${ }^{\mathrm{T}}$ and $\mathrm{RO} 1-22$, as a new species of the genus.

Strains RO1-28 ${ }^{\mathrm{T}}$ and RO1-22 were isolated from sediment of the Rudong solar saltern $\left(32.2699^{\circ} \mathrm{N} 121.3999^{\circ} \mathrm{E}\right)$ in Jiangsu province, China. The neutral oligotrophic haloarchaeal medium (NOM) used for the isolation pro- 
cedure was modified according to the DBCM2 medium from the online Halohandbook (Dyall-Smith, 2008) and contained the following ingredients $\left(1^{-1}\right)$ : yeast extract, $0.05 \mathrm{~g}$; fish peptone, $0.25 \mathrm{~g}$; sodium pyruvate, $1.0 \mathrm{~g}$; $\mathrm{KCl}, 5.4 \mathrm{~g} ; \mathrm{K}_{2} \mathrm{HPO}_{4}, 0.3 \mathrm{~g} ; \mathrm{CaCl}_{2}, 0.25 \mathrm{~g} ; \mathrm{NH}_{4} \mathrm{Cl}, 0.25 \mathrm{~g}$; $\mathrm{MgSO}_{4} \cdot 7 \mathrm{H}_{2} \mathrm{O}, 26.8 \mathrm{~g} ; \mathrm{MgCl}_{2} \cdot 6 \mathrm{H}_{2} \mathrm{O}, 23.0 \mathrm{~g} ; \mathrm{NaCl}, 184.0 \mathrm{~g}$ ( $\mathrm{pH}$ adjusted to 7.0-7.2 with $1 \mathrm{M} \mathrm{NaOH}$ solution). The medium was solidified with $2.0 \%$ agar. Strains were routinely grown aerobically at $37{ }^{\circ} \mathrm{C}$ in a modified $\mathrm{R} 2 \mathrm{~A}$ medium (MR2A) containing the following ingredients $\left(1^{-1}\right)$ : Casamino acids (Difco), $0.5 \mathrm{~g}$; yeast extract (Difco), $0.5 \mathrm{~g}$; sodium pyruvate, $0.5 \mathrm{~g}$; fish peptone, $0.5 \mathrm{~g}$; glucose, $0.5 \mathrm{~g}$; sodium glutamate, $0.5 \mathrm{~g}$; trisodium citrate, $3.0 \mathrm{~g}$; $\mathrm{KCl}, 2.0 \mathrm{~g} ; \mathrm{K}_{2} \mathrm{HPO}_{4}, 0.3 \mathrm{~g} ; \mathrm{CaCl}_{2}, 0.5 \mathrm{~g} ; \mathrm{MgSO}_{4} .7 \mathrm{H}_{2} \mathrm{O}$, 20 g; NaCl, 200.0 g (pH 7.0-7.2).

Phenotypic tests were performed according to the proposed minimal standards for the description of novel taxa in the order Halobacteriales (Oren et al., 1997). The type strains Haladaptatus paucihalophilus JCM $13897^{\mathrm{T}}$, Haloferax volcanii CGMCC $1.2150^{\mathrm{T}}$ and Haloplanus natans JCM $14081^{\mathrm{T}}$ were selected as reference strains in positive and negative testing. Cell morphology and motility in exponentially growing liquid cultures were examined using a Leica microscope equipped with phase-contrast optics (model DM LB2). For scanning electron microscopy examination, $0.5 \mathrm{ml}$ samples were fixed overnight at $4{ }^{\circ} \mathrm{C}$ by adding glutaraldehyde to a final concentration of $5.0 \%$. A $10 \mu \mathrm{l}$ sample was smeared on a polylysine-coated coverslip, and air-dried. The coverslip was then serially dehydrated in 40,70, 90 and $100 \%$ ethanol solutions (10 min at each stage), critical-point dried, mounted on a specimen stub, sputter-coated with gold and viewed in a Hitachi S-4800 scanning electron microscope.

The Gram stain was performed by following the method outlined by Dussault (1955). Growth and gas formation with nitrate as electron acceptor were tested in $10 \mathrm{ml}$ stoppered tubes, completely filled with liquid growth medium to which $\mathrm{NaNO}_{3}\left(5 \mathrm{~g} \mathrm{l}^{-1}\right)$ had been added, and containing an inverted Durham tube. The formation of nitrite was monitored colorimetrically. Anaerobic growth in the presence of L-arginine and DMSO $\left(5 \mathrm{~g} \mathrm{l}^{-1}\right)$ was tested in completely filled $10 \mathrm{ml}$ stoppered tubes. Starch hydrolysis was determined on MR2A agar plates supplemented with $2 \mathrm{~g}$ soluble starch per litre and detected by flooding the plates with Lugol's iodine solution. Gelatin hydrolysis was performed by growing colonies on MR2A agar plates amended with $0.5 \%(\mathrm{w} / \mathrm{v})$ gelatin and flooding the plates with Frazier reagent after growth was established. Esterase activity was detected as outlined by Gutiérrez \& González (1972). Tests for catalase and oxidase activities were performed as described by Gonzalez et al. (1978). Production of $\mathrm{H}_{2} \mathrm{~S}$ was tested by growing the isolates and reference strains in a tube with the MR2A liquid medium supplemented with $0.5 \%(\mathrm{w} / \mathrm{v}) \mathrm{Na}_{2} \mathrm{~S}_{2} \mathrm{O}_{3}$; a filter-paper strip impregnated with lead acetate was used for $\mathrm{H}_{2} \mathrm{~S}$ detection. The other miscellaneous biochemical tests and nutrition tests were performed as described and cited by
Bardavid et al. (2007). Sensitivity to antimicrobial agents was performed as described by Gutiérrez et al. (2008).

Cells of strains RO1- $28^{\mathrm{T}}$ and RO1-22 were non-motile, coccus-shaped $(1.0-1.5 \mu \mathrm{m})$ (Supplementary Fig. S1, available in IJSEM Online), Gram-stain-negative and were able to grow in a wide range of salinities (1.7-5.1 M NaCl; optimal growth at $3.4 \mathrm{M}$ and $4.3 \mathrm{M}$, respectively). Cells did not lyse in distilled water and remained viable under these conditions for up to 2 weeks. Colonies on MR2A agar were pink-pigmented. Both strains utilized D-glucose, D-mannose, maltose, D-galactose and sucrose but not D-fructose or lactose as carbon sources for growth. The novel strains were not able to grow with DMSO, nitrate, nitrite or arginine under anaerobic conditions. More detailed results of phenotypic tests and nutritional features of strains RO1$28^{\mathrm{T}}$ and RO1-22 are given in the species description. Characteristics that distinguish strains RO1- $28^{\mathrm{T}}$ and RO122 from the two described strains of Haladaptatus paucihalophilus are shown in Table 1.

Polar lipids were extracted using a chloroform/methanol system and analysed using one- and two-dimensional TLC, as described previously (Kates, 1986). Merck silica gel 60 $\mathrm{F}_{254}$ aluminium-backed thin-layer plates were used in TLC analysis. The plate dotted with sample for detecting phospholipids was subjected to two-dimensional development, with the first solvent of chloroform/methanol/ water $(65: 25: 4$, by vol.) and followed by the second solvent of chloroform/methanol/acetic acid/water (85: $12: 15: 4$, by vol.). The plate for detecting glycolipids was subjected to single development in the solvent chloroform/ methanol/acetic acid/water $(85: 22.5: 10: 4$, by vol.). Strains RO1-28 ${ }^{\mathrm{T}}$ and RO1-22 contained phosphatidylglycerol (PG), phosphatidylglycerol phosphate methyl ester (PGP-Me), phosphatidylglycerol sulfate (PGS) and three glycolipids, in a pattern chromatographically identical to the polar lipid profile of Haladaptatus paucihalophilus JCM $13897^{\mathrm{T}}$ (see Supplementary Fig. S2). Among the three glycolipids, one of them (GL2) was chromatographically identical to S-DGD-1 of Haloferax volcanii CGMCC $1.2150^{\mathrm{T}}$ and Haloplanus natans JCM $14081^{\mathrm{T}}$, the remaining two (GL1 \& GL3) were still unidentified (see Supplementary Fig. S2b, c). The polar lipid composition supports classification of strains RO1-28 ${ }^{\mathrm{T}}$ and RO1-22 in the genus Haladaptatus.

Genomic DNA from halophilic archaeal strains was prepared as described by $\mathrm{Ng}$ et al. (1995). The 16S rRNA gene was amplified by PCR, using primers $0018 \mathrm{~F}$ and $1518 \mathrm{R}$ (Cui et al., 2009). The amplified products were cloned into the pEASY-T vector (TransGen Biotech) and transformed into Escherichia coli Mach1. Thirty clones of each novel strain were randomly picked and sequenced at the SinoGenoMax Company Limited (Beijing, China), to determine whether the two strains possessed multiple distinct $16 \mathrm{~S}$ rRNA gene sequences. Multiple sequence alignments were performed using the CLUSTAL $\mathrm{W}$ program integrated into the MEGA4 software (Tamura et al., 2007). 
Table 1. Characteristics that distinguish strains $\mathrm{RO} 1-28^{\top}$ and $\mathrm{RO} 1-22$ from Haladaptatus paucihalophilus $\mathrm{JCM} 13897^{\top}$ and GY252

Strains: 1, Strain RO1-28 ${ }^{\mathrm{T}}$; 2, Strain RO1-22; 3, Haladaptatus paucihalophilus DX253 ${ }^{\mathrm{T}}=\mathrm{JCM} 13897^{\mathrm{T}}$; 4 , Haladaptatus paucihalophilus GY252. + , Positive; -, negative; NR, not reported; w, weakly positive. The table is based on direct comparison of the phenotypic properties of the type strains, as well as on published data for the two strains of Haladaptatus paucihalophilus (Savage et al., 2007).

\begin{tabular}{|c|c|c|c|c|}
\hline Characteristic & 1 & 2 & 3 & 4 \\
\hline Optimum $\mathrm{NaCl}(\mathrm{M})$ & 3.4 & 4.3 & 3.1 & 2.6 \\
\hline $\mathrm{NaCl}$ range $(\mathrm{M})$ & $1.7-5.1$ & $1.7-5.1$ & $0.8-5.1$ & $0.8-5.1$ \\
\hline Optimum pH & 7.0 & 7.0 & 6.5 & 6.0 \\
\hline $\mathrm{pH}$ range & $6.0-8.5$ & $6.0-8.5$ & $5.0-7.5$ & $5.0-7.5$ \\
\hline Nitrate reduction & + & + & - & - \\
\hline Fructose & - & - & + & + \\
\hline Xylose & - & - & + & + \\
\hline Mannitol & + & - & + & + \\
\hline L-Malate & - & - & + & + \\
\hline Citrate & - & - & + & + \\
\hline L-Alanine & + & $\mathrm{W}$ & - & - \\
\hline
\end{tabular}

${ }^{\star}$ Determined in this study.

Phylogenetic trees were reconstructed using the neighbourjoining (Saitou \& Nei, 1987) and maximum-parsimony (Fitch, 1971) methods in the MEGA4 software. The percentages of replicate trees in which the associated taxa clustered together in the bootstrap test (1000 replicates) were calculated. 16S rRNA gene sequence similarity was calculated by comparison with sequences of related halophilic archaea from the online EzTaxon server (Chun et al., 2007).

Thirty complete 16S rRNA gene sequences (1472 nt each) of strains RO1-28 ${ }^{\mathrm{T}}$ and RO1-22 were obtained. Sequence comparisons indicated that both strains had only one kind of $16 \mathrm{~S}$ rRNA gene sequence; they were $99.7 \%$ similar to each other. Both strains were closely related to Haladaptatus paucihalophilus, the single species of the genus Haladaptatus, with similarities of 94.0-95.2\%. Phylogenetic analysis using the neighbour-joining algorithm revealed that strain $\mathrm{RO} 1-28^{\mathrm{T}}$ and strain $\mathrm{RO} 1-22$ clustered with Haladaptatus paucihalophilus, forming a branch in the cluster with a bootstrap value of $100 \%$ (Fig. 1). The phylogenetic position was also confirmed in a tree generated using the maximum-parsimony algorithm (see Supplementary Fig. S3).

The DNA $\mathrm{G}+\mathrm{C}$ content was determined by using the HPLC method of Mesbah et al., (1989). DNA-DNA hybridization analyses were performed according to the thermal denaturation and renaturation method of De Ley et al. (1970) as modified by Huß et al. (1983). Both strains RO1-28 ${ }^{\mathrm{T}}$ and RO1-22 had a DNA G $+\mathrm{C}$ content of
54.0 mol\%, a relatively low value when compared with Haladaptatus paucihalophilus $(60.5 \mathrm{~mol} \%$ reported in the literature; $59.2 \mathrm{~mol} \%$ determined in this study). The DNA relatedness between strains $\mathrm{RO} 1-28^{\mathrm{T}}$ and RO1-22 was $92 \%$. The data show that the two strains should be classified as members of the same species, since the generally accepted threshold value to separate two species is $70 \%$ (Stackebrandt \& Goebel, 1994). The DNA relatedness between strains $\mathrm{RO} 1-28^{\mathrm{T}}$ and $\mathrm{RO} 1-22$, and Haladaptatus paucihalophilus JCM $13897^{\mathrm{T}}$ was $32 \%$ and $33 \%$, respectively.

On the basis of their phenotypic and chemotaxonomic characteristics, including low levels of DNA-DNA relatedness to Haladaptatus paucihalophilus JCM $13897^{\mathrm{T}}$, strains RO1-28 ${ }^{\mathrm{T}}$ and RO1-22 are considered to represent a novel species of the genus Haladaptatus, for which the name Haladaptatus litoreus sp. nov. is proposed.

\section{Emended description of the genus Haladaptatus Savage et al. 2007}

Gram-negative cocci or coccobacilli occurring singly or in pairs. Cells did not lyse in distilled water. Colonies are pink-pigmented. Some species possess at least two heterogeneous 16S rRNA gene sequences. Cells contain PG, PGP-Me and PGS. Three glycolipids are present; one of them is chromatographically identical to S-DGD-1, the others are unidentified. Chemo-organotrophic, growing on a wide range of substrates, including single and complex carbon sources. Produce acid from carbohydrates. 


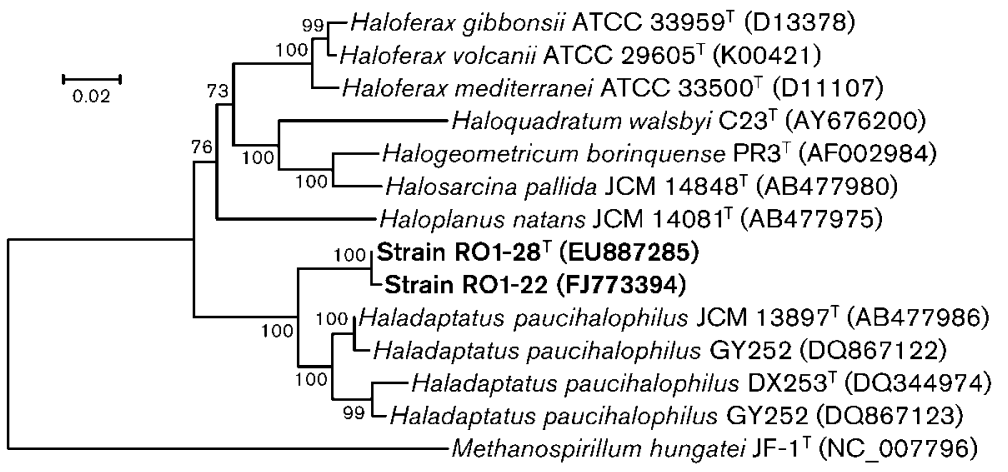

\begin{abstract}
Fig. 1. Neighbour-joining phylogenetic tree based on 16S rRNA gene sequences showing the relationship between the members of the genus Haladaptatus and related genera within the family Halobacteriaceae. Bootstrap values (\%) are based on 1000 replicates and are shown for branches with more than $70 \%$ bootstrap support. Bar, 0.02 substitutions per nucleotide position.
\end{abstract}

Hydrolyse casein, starch, gelatin and Tween 80 . Grow at a wide range of $\mathrm{NaCl}$ concentrations. Sensitive to novobiocin, bacitracin and rifampicin. Resistant to erythromycin, penicillin, ampicillin, chloramphenicol, neomycin, nalidixic acid and gentamicin. The DNA $\mathrm{G}+\mathrm{C}$ content is between 54.0 and $60.5 \mathrm{~mol} \%$. Isolated from low-salt, sulfide- and sulfur-rich spring and saltern crystallizer ponds. The type species is Haladaptatus paucihalophilus.

\section{Description of Haladaptatus litoreus sp. nov.}

Haladaptatus litoreus (li.to're.us. L. masc. adj. litoreus living near the sea, of or belonging to the seashore).

Cells are non-motile, coccus-shaped (1.0-1.5 $\mu \mathrm{m})$ and Gram-stain-negative. Colonies on MR2A agar plates containing $3.4 \mathrm{M} \mathrm{NaCl}$ are pink, elevated and round. Chemo-organotrophic and aerobic. Growth occurs at $\mathrm{NaCl}$ concentrations of $1.7-5.1 \mathrm{M}$, at $\mathrm{Mg}^{2+}$ concentrations of 0.05-0.7 $\mathrm{M}$, at $\mathrm{pH}$ values in the range 6.0-8.5, and within the temperature range $25-55{ }^{\circ} \mathrm{C}$. Optimal $\mathrm{NaCl}$ concentration, $\mathrm{pH}$ and temperature for growth are $3.4 \mathrm{M}, 7.0$ and 37-40 ${ }^{\circ} \mathrm{C}$, respectively. Catalase- and oxidase-positive. Does not grow under anaerobic conditions with nitrate, arginine and DMSO. Nitrate reduction to nitrite is observed. $\mathrm{H}_{2} \mathrm{~S}$ is not produced from $\mathrm{Na}_{2} \mathrm{~S}_{2} \mathrm{O}_{3}$. Positive for indole formation. Tweens 20, 40, 60 and 80 are hydrolysed. Positive for caseinase, amylase and gelatinase. The following substrates are utilized as carbon sources for growth: D-glucose, D-mannose, D-galactose, maltose, sucrose, starch, glycerol, D-mannitol, acetate, pyruvate, DL-lactate, fumarate, L-alanine, L-arginine, L-aspartate, L-glutamate and L-ornithine. D-Fructose, L-sorbose, D-ribose, D-xylose, lactose, D-sorbitol, succinate, L-malate, citrate, glycine and L-lysine are not utilized as carbon sources. Produces acid when grown on D-glucose, D-galactose, sucrose, starch, maltose and glycerol. Sensitive to the following antibiotics ( $\mu$ g or IU per disc): rifampicin (5), novobiocin (30), bacitracin (0.04 IU) and norfloxacin (10). Resistant to the following antibiotics: erythromycin (15), neomycin (30), chloramphenicol (30), ampicillin (10), penicillin G (10 IU), ciprofloxacin (5), streptomycin (10), kanamycin (30), tetracycline (30), vancomycin (30), gentamicin (10) and nalidixic acid
(30). The major polar lipids are PG, PGP-Me, PGS and three glycolipids, similar to the polar lipid profile of Haladaptatus paucihalophilus JCM $13897^{\mathrm{T}}$. The DNA $\mathrm{G}+\mathrm{C}$ content of the type strain is $54.0 \%$ (HPLC).

The type strain is RO1-28 $8^{\mathrm{T}}$ (=CGMCC $1.7737^{\mathrm{T}}=\mathrm{JCM}$ $15771^{\mathrm{T}}$ ), and was isolated from Rudong solar saltern in Jiangsu province, China.

\section{Acknowledgements}

This work was supported by the National Science \& Technology Infrastructure Program of China (2005DKA2120611), a grant from Jiangsu Department of Education (Grant No. 08 kJB180002), a startup grant from Jiangsu University (Grant No. 08JDG016) and two scientific training grants for senior students from Jiangsu Department of Education and Jiangsu University.

\section{References}

Bardavid, R. E., Mana, L. \& Oren, A. (2007). Haloplanus natans gen. nov., sp. nov., an extremely halophilic, gas-vacuolate archaeon isolated from Dead Sea-Red Sea water mixtures in experimental outdoor ponds. Int J Syst Evol Microbiol 57, 780-783.

Chun, J., Lee, J.-H., Jung, Y., Kim, M., Kim, S., Kim, B. K. \& Lim, Y.-W. (2007). EzTaxon: a web-based tool for the identification of prokaryotes based on $16 \mathrm{~S}$ ribosomal RNA gene sequences. Int J Syst Evol Microbiol 57, 2259-2261.

Cui, H.-L., Zhou, P.-J., Oren, A. \& Liu, S.-J. (2009). Intraspecific polymorphism of 16S rRNA genes in two halophilic archaeal genera, Haloarcula and Halomicrobium. Extremophiles 13, 31-37.

De Ley, J., Cattoir, H. \& Reynaerts, A. (1970). The quantitative measurement of DNA hybridization from renaturation rates. Eur $J$ Biochem 12, 133-142.

Dussault, H. P. (1955). An improved technique for staining red halophilic bacteria. J Bacteriol 70, 484-485.

Dyall-Smith, M. L. (2008). The Halohandbook: Protocols for haloarchaeal genetics. http://www.haloarchaea.com/resources/halohandbook/.

Fitch, W. M. (1971). Toward defining the course of evolution: minimum change for a specific tree topology. Syst Zool 20, 406-416.

Gonzalez, C., Gutierrez, C. \& Ramirez, C. (1978). Halobacterium vallismortis sp. nov. An amylolytic and carbohydrate-metabolizing, extremely halophilic bacterium. Can J Microbiol 24, 710-715.

Gutiérrez, C. \& González, C. (1972). Method for simultaneous detection of proteinase and esterase in extremely halophilic bacteria. Appl Microbiol 24, 516-517. 
Gutiérrez, M. C., Castillo, A. M., Kamekura, M. \& Ventosa, A. (2008). Haloterrigena salina sp. nov., an extremely halophilic archaeon isolated from a salt lake. Int J Syst Evol Microbiol 58, 2880-2884.

Huß, V. A. R., Festl, H. \& Schleifer, K. H. (1983). Studies on the spectrophotometric determination of DNA hybridization from renaturation rates. Syst Appl Microbiol 4, 184-192.

Kates, M. (1986). In Techniques of Lipidology, 2nd rev. edn, pp. 106107, 187-188 and 251-254. Amsterdam: Elsevier.

Mesbah, M., Premachandran, U. \& Whitman, W. B. (1989). Precise measurement of the $\mathrm{G}+\mathrm{C}$ content of deoxyribonucleic acid by high-performance liquid chromatography. Int J Syst Bacteriol 39, 159-167.

Ng, W. L., Yang, C. F., Halladay, J. T., Arora, A. \& DasSarma, S. (1995). Protocol 25. Isolation of genomic and plasmid DNAs from Halobacterium halobium. In Archaea: a Laboratory Manual: Halophiles, pp. 179-180. Edited by S. DasSarma \& E. M. Fleischmann. Cold Spring Harbor, NY: Cold Spring Harbor Laboratory.

Oren, A. (2006). The order Halobacteriales. In The Prokaryotes: a Handbook on the Biology of Bacteria, 3rd edn, vol. 3, pp. 113-164. Edited by M. Dworkin, S. Falkow, E. Rosenberg, K.-H. Schleifer \& E. Stackebrandt. New York: Springer.
Oren, A., Ventosa, A. \& Grant, W. D. (1997). Proposed minimal standards for description of new taxa in the order Halobacteriales. Int J Syst Bacteriol 47, 233-238.

Purdy, K. J., Cresswell-Maynard, T. D., Nedwell, D. B., McGenity, T. J., Grant, W. D., Timmis, K. N. \& Embley, T. M. (2004). Isolation of haloarchaea that grow at low salinities. Environ Microbiol 6, 591-595.

Saitou, N. \& Nei, M. (1987). The neighbor-joining method: a new method for reconstructing phylogenetic trees. Mol Biol Evol 4, 406-425.

Savage, K. N., Krumholz, L. R., Oren, A. \& Elshahed, M. S. (2007) Haladaptatus paucihalophilus gen. nov., sp. nov., a halophilic archaeon isolated from a low-salt, sulfide-rich spring. Int J Syst Evol Microbiol 57, 19-24.

Savage, K. N., Krumholz, L. R., Oren, A. \& Elshahed, M. S. (2008). Halosarcina pallida gen. nov., sp. nov., a halophilic archaeon from a low-salt, sulfide-rich spring. Int J Syst Evol Microbiol 58, 856-860.

Stackebrandt, E. \& Goebel, B. M. (1994). Taxonomic note: a place for DNA-DNA reassociation and $16 \mathrm{~S}$ rRNA sequence analysis in the present species definition in bacteriology. Int J Syst Bacteriol 44, 846-849.

Tamura, K., Dudley, J., Nei, M. \& Kumar, S. (2007). MEGA4: molecular evolutionary genetics analysis (MEGA) software version 4.0. Mol Biol Evol 24, 1596-1599. 